\title{
Article
}

\section{James Christensen*}

\section{Egalitarian Trade Justice}

https://doi.org/10.1515/mopp-2021-0031

Published online September 28, 2021

\begin{abstract}
This article begins by distinguishing between two approaches to egalitarian trade justice - the explicative approach and the applicative approach - and notes that the former has been used to defend conclusions that are less strongly egalitarian than those defended by advocates of the latter. The article then engages with the primary explicative account of trade egalitarianism - that offered by Aaron James - and argues that its egalitarian conclusions are unduly minimalistic. The aim of the article is not to criticize the explicative approach, but rather to show that the arguments and commitments of its best-known defender - James - either fail to rule out, or in fact positively support, more robustly egalitarian conclusions.
\end{abstract}

Keywords: international trade, egalitarianism, equality, distributive justice, Aaron James

\section{Introduction}

In recent decades, notions of fair and just trade have become increasingly widespread. These ideas are invoked by politicians, protesters, workers, consumers, and corporations. The belief that trade is currently unfair or unjust is ubiquitous, though there is considerable disagreement about where, exactly, the unfairness or injustice lies, and, relatedly, about what must be done to rectify the situation. Resolving these disagreements will be crucial if we are to succeed in reconciling ourselves to the globalized world in which we live, and in resisting calls for a return to more parochial modes of production and exchange.

Among political philosophers, it is common to claim that justice in trade requires some kind of equality (Brandi 2014; Christensen 2017; Garcia 2003; James 2012; Moellendorf 2005; Suttle 2017). Often, the claim is that the national income gains that trade makes possible should, at the bar of justice, be distributed in an

\footnotetext{
*Corresponding author: James Christensen, Department of Government, University of Essex, Wivenhoe Park, Colchester, C04 3SQ, UK, E-mail: james.christensen@essex.ac.uk. https://orcid. org/0000-0003-2722-7486
} 
egalitarian fashion. Trade egalitarianism has been defended in a variety of different ways, but, for present purposes, it will be helpful to distinguish between two broad approaches. The first approach begins with a general commitment to equality and then identifies the implications of that value for trade. Advocates of this approach argue that trade must be arranged in a manner that adequately promotes a value that we have trade-independent reason to endorse (Christensen 2017, pp. 140-142). Because this approach begins from a commitment to equality as a freestanding value, and then applies that value to trade, we can refer to it as the applicative approach.

The second approach, by contrast, does not begin with a general commitment to equality. Rather, it begins with the practice of trade, and with an account that identifies that practice's nature, aims, and key participants. In light of the account that they provide, advocates of this approach then argue that an egalitarian principle is appropriate for trade practice - regardless of that principle's appeal, or lack thereof, in other contexts (James 2012). Because this approach begins with an explication of the nature of trade practice - and searches for a principle suited to that nature - we can refer to it as the explicative approach.

This first distinction - between applicative and explicative approaches - has, in practice, coincided with a second, looser, distinction between stronger and weaker forms of trade egalitarianism. The explicative approach has been used to defend conclusions that are less strongly egalitarian than those defended by proponents of the applicative alternative. In this paper, I engage with the primary explicative account of trade egalitarianism - that offered by Aaron James - and argue that its egalitarian conclusions are unduly minimalistic. My aim is not to criticize the explicative approach, but rather to show that the arguments and commitments of its best-known defender - James - either fail to rule out, or in fact positively support, more robustly egalitarian conclusions. I will not claim that James's explicative approach can yield egalitarian conclusions that are as strong as those produced by the applicative alternative, but I will contend that James's approach can accommodate egalitarian conclusions stronger than those he in fact endorses. I hope to move the debate about trade justice forward by demonstrating that proponents of the explicative approach can endorse egalitarian conclusions of similar strength to those embraced by proponents of the applicative alternative, despite approaching the subject in a very different - and apparently more parsimonious - manner.

Before proceeding, it will be helpful to foreground the ways in which the trade egalitarianism associated with James's explicative approach is weaker than the trade egalitarianism associated with the applicative alternative. The divergences concern how each approach treats two sets of inequalities. The first set of inequalities are those that exist between those who participate in trade: put simply, 
some trading nations are better-off (in terms of a variety of familiar indicators) than others. The second set of inequalities are a subset of those that concern how the gains from trade are distributed among participants, namely, inequalities in the distribution of gains that reflect differential features of the respective nations' makeup. Nations differ in terms of their population size, geography, climate, etc., and these differential "national endowments" affect how much each nation gains from trade (James 2012, p. 222).

Let us consider these two types of inequality - and how they are treated by explicative and applicative approaches - in reverse order, beginning with inequalities of gain that are attributable to differential national endowments. James claims that these inequalities do not represent a departure from justice and should therefore be tolerated. As we shall see, James defends this claim from the perspective of his explicative approach, and, more specifically, by appealing to a particular account of the trade regime's nature.

The applicative approach takes a contrasting approach to inequalities attributable to differential national endowments. Because this approach begins from a commitment to equality as a freestanding value, inequalities in national endowment are themselves liable to normative evaluation. Because such inequalities may be deemed unjust - e.g., because they fail to track factors such as choice or responsibility, which a general egalitarian outlook may regard as morally relevant, and are therefore morally arbitrary - any influence they exert on the distribution of the gains from trade may also be unjust. Such inequalities are thus liable to regulation (Christensen 2017, p. 141).

In Section 3, I will show that James's reasons for tolerating inequalities attributable to differential national endowments are insufficiently motivated by his explicative approach. I will argue that James should thus condemn such inequalities.

Now consider the inequalities that exist among nations that participate in the trade practice. These inequalities could potentially be regarded as unjust by both applicative and explicative approaches. Because the applicative approach endorses equality as a general ideal, it has reasons to condemn inequalities that arise between nations (and/or their individual members) regardless of whether or not they trade. By contrast, while the explicative does not affirm equality as a freestanding value, it might condemn inequalities between trading nations qua participants in the trade practice. Such condemnation might reflect, for example, the conviction that inequality among participants can undermine the fairness of the practice (e.g., by sustaining large differences in bargaining power) (e.g., Beitz 2001, pp. 8-9).

Accordingly, both applicative and explicative approaches can have reasons to favour a distribution of gains that is not equal but equalizing. ${ }^{1}$ In other words, both 
approaches can recommend giving a larger share to worse-off nations as a means to narrowing the gap between those more- and less-advantaged.

James does advocate for a distribution that has an equalizing effect (though his defence of that distribution does not appeal to its equalizing effect). ${ }^{2}$ He argues that departures from equality can be justified when they work to the advantage of poorer trading nations. However, in Section 2, I will argue that James's proposals are weaker in their egalitarianism than alternatives that he has positive reasons to endorse.

\section{In Defence of Greater Pro-poor Inequality}

James's explication of trade practice focuses on its cooperative nature. James identifies the trade regime as one part of a larger "market reliance practice" (2012, p. 19), which he characterizes as "a form of international cooperation, for mutual national advantage” (2012, p. 30). In starting with a conception of the global economy as a cooperative enterprise, James's theory of trade justice hews closely to John Rawls's highly influential theory of social justice, which begins with a conception of domestic society as a cooperative enterprise. For Rawls, specifying an appropriate distribution of the advantages that cooperation makes possible is a primary role of any theory of justice. Rawls tells his readers that the "intuitive idea" behind the egalitarian principles he favours is that "the division of advantages should be such as to draw forth the willing cooperation of everyone taking part"; the principles in question specify "a fair basis on which those better endowed ... could expect the willing cooperation of others...” (Rawls 1999, p. 13). Extending Rawlsian ideas to the global domain, James argues that the gains from trade should be distributed equally among all trading nations.

Briefly stated, James's argument for an equal distribution of the gains from trade is as follows. Trading countries are moral equals; they have comparable interests in greater rather than smaller gains; and they have no special claim to a larger share. Importantly, trading countries are seen as "co-creating" the gains from trade (James 2012, p. 168). These gains are "the fruit of international social cooperation" in which all trading countries can be seen as full participants (James

1 This term is borrowed from Armstrong (2013, p. 333). For an applicative justification for an equalizing distribution of the gains from trade, see Christensen (2017, pp. 141-2).

2 James is motivated by the prioritarian conviction that gains to the less advantaged matter more than gains to the better-off. His favoured distribution has the consequence of narrowing inequalities between rich and poor trading countries, but this is a side-effect of the distribution, not its aim. I return to this point in my conclusion (James 2012, pp. 223-224). 
2012, p. 168). James tells us that this is his "main idea" (2012, p. 168). Taken together, these considerations are thought to ground a presumption in favour of an equal distribution.

As noted in the previous section, James's international egalitarian principle which he calls "International Relative Gains" - does not recommend a strictly equal distribution. Departures from equality are permitted when they reflect one of two considerations. Firstly, inequality of gain is permitted when greater gains accrue to countries that are poor. James tells us that "gains to each trading society ... are to be distributed equally, unless unequal gains flow (e.g., via special trade privileges) to poor countries” (James 2012, pp. 18, 203). As I previously intimated, this departure from equality does not have to be framed as a departure from egalitarianism. A principle that grants a larger share to poorer countries can be conceived as a step toward equalizing the positions of rich and poor countries (or at least narrowing the inequality between them), and thus as egalitarian. In this section, I shall argue that James's own commitments suggest he should take such equalizing further than he in fact does.

In the next section, I will consider James's second ground for permissible inequality, which relates to "national endowments": that is, features of a country's makeup that exist independently of trade and affect the level of gain that a country can be expected to reap. James tells us that "gains are to be adjusted according to relevant endowments such as a country's population size, natural resource base, level of development, and any other factor not created by the trade relation that predictably changes how much a country gains from global market integration" (James 2012, p. 222). James claims that when inequalities are attributable to differential endowments, they should be permitted. I will argue that James's account does not mandate this departure from equality.

We should begin our analysis by trying to get a clearer picture of what exactly is recommended by International Relative Gains (bracketing, until the next section, the second ground for permissible inequality that it specifies). We can do this by introducing a distinction between ex post and ex ante distribution. For present purposes, ex post distribution refers to the reallocation of goods that have already been distributed once through market mechanisms (or through some combination of market and non-market mechanisms). By contrast, ex ante distribution refers to the implementation of measures whose purpose is to alter the expected distributive outcomes of market exchange.

In the case at hand, ex post distribution would involve allowing trade to occur, waiting for gains to accrue, and then redistributing these gains according to an egalitarian pattern. (To the extent that trade is ongoing, redistribution will never be literally "after the fact". Rather, trading activity would be divided into (perhaps arbitrarily specified) "rounds", with gains tallied up and redistributed at the end of 
each one.) By contrast, ex ante distribution would involve organizing the system in such a way that the gains from trade predictably or "automatically" fall out in a manner that more closely approximates an egalitarian pattern (Gerhart 2002).

International Relative Gains is clearly supposed to involve ex ante distribution. As we have seen, when setting out his first ground for permissible inequality, James writes that unequal gains are permitted when they "flow (e.g., via special trade privileges) to poor countries.” The parenthetical example is instructive. Special trade privileges - which might, for example, allow rich countries to offer better than Most Favoured Nation treatment to their poorer trading partners - are clearly an example of ex ante distribution. As further examples of mechanisms that might allow greater gains to "flow" to poor countries, James mentions "technological and infrastructural assistance" and exemptions "from specific intellectual property, services, investment, or competition rules” (James 2012, p. 222). As James has explained in work published subsequent to the initial statement of his theory, poor countries are to be allowed to trade to dynamic comparative advantage. Rather than simply specializing in the production of those goods that they can currently produce more efficiently than any other (which would be to specialize according to static comparative advantage, and which might offer limited opportunities for economic advancement), poor countries should be "allowed or even encouraged" to develop their productive capacities so as to acquire a comparative advantage in more profitable sectors (James 2017, p. 276). James acknowledges that rich countries may be worse-off as a result of such arrangements - e.g. because they lose their dominant position within a particular industry or have to devote more of their gains to compensating those of their citizens who are harmed by trade - but he maintains that these countries can reasonably be asked to bear such costs (James 2017, p. 278).

The proposal here is to give poor countries the tools and space that they need to make the most of trade. The aim is to ensure that poor countries are competitive, and can thus do well for themselves, reaping the benefits of market activity rather than relying on "handouts" from their richer trading partners. Given the ex ante nature of what is being proposed, James's reference to gains "flowing" to poor countries seems apt. It alludes to a sense in which benefits are "naturally" accruing to poor countries throughout the course of market activity, rather than being reallocated to poor countries in an attempt to "correct" market outcomes that have not been to their advantage.

Considering the Rawlsian pedigree of much of James's argument, this emphasis on ex ante distribution is hardly surprising. It comports with Rawls's own favoured methods for securing distributive justice, and, in particular, with his preference for "property owning democracy" over "welfare state capitalism". Rawls maintained that the point of appropriately designed distributive institutions 
"is not simply to assist those who lose out through accident or misfortune (although that must be done), but rather to put all citizens in a position to manage their own affairs on a footing of a suitable degree of social and economic equality" (Rawls 2001, p. 139). Analogously, we might hold that, insofar as it serves as a distributive institution, the trade system should aim to ensure that all member states can manage their own affairs and participate on a footing of social and economic equality.

However, Rawls's acknowledgement that distributive institutions will inevitably also have to "assist those who lose out through accident or misfortune" is important, and it is unlikely that James thinks of International Relative Gains as requiring only ex ante distribution. Since ex post measures are undoubtedly what many (if not most) people have in mind when they think of distributive mechanisms, it would be odd to discover that James did not envisage a role for such measures. If he really did expect egalitarian trade justice to be realized through ex ante measures alone, he surely would have made this explicit. $^{3}$

So, what might the ex post element of the proposed distributive arrangements look like? In light of what has been said so far, the following is a natural reading of what James has in mind. At the end of a "round" of trade, we tally up the gains that have been produced and calculate what each country would receive if this total were distributed equally. We then compare the size of the shares that each country would enjoy if gains were distributed equally with the size of the shares that each country has actually acquired. If a country (i) is rich and (ii) has received a larger than equal share of the total, its excess gains are redistributed to those countries that have received a smaller than equal share, thereby rectifying the latter countries' initial shortfall. If only rich countries have received larger than equal shares, ex post redistribution will eliminate inequality of gain. By contrast, if a poor country has received a larger than equal share, it will be permitted to keep its larger share, meaning that some other country or countries will have to settle for a smaller than equal share. An important point to note is that, on this reading, ex post redistribution is not used to secure disproportionately large gains for poor countries; such redistribution is used only to reallocate any disproportionately large

3 It is also worth noting that Rawls recognized an additional function of ex post distribution, namely, the regulation and correction of departures from just background conditions. These departures are not merely accidents, but rather the accumulated results of many formally fair agreements. Reflection on Rawlsian concerns about background injustice - which emphasize the limitations of contracts and market transactions (or, when transposed to the international level, of specific trade agreements and global supply chains) - suggests an additional reason to think that James would endorse some form of ex post redistribution. On global background injustice, see Ronzoni (2009). I thank an anonymous reviewer for highlighting this point. 
gains received by richer countries, thereby rectifying the concomitant shortfalls associated with those larger gains. In other words, ex post redistribution is a means for addressing unjust inequalities, not for creating just inequalities.

This reading of James's account chimes with his oft repeated suggestion that inequality of gain is to be welcomed when greater than equal gains "flow" to poor countries. The "flow" metaphor (which invites one to think of a natural process) seems inappropriate when gains have been redirected in order to manufacture the inequalities in question. If this is not what James had in mind, my hope is that the present discussion can nevertheless serve valuable functions. It can expose an important unclarity in James's view; identify different forms that an egalitarian distribution of the gains from trade might take; and offer reasons (compatible with James's general approach) for favouring one of those forms - the more egalitarian one - over others.

I want to voice three reservations about the envisaged distributive scheme. More specifically, I want to identify three ways in which the scheme appears to fall short of James's own egalitarian commitments. My first and second reservations focus on the ex post element of the scheme; the third concerns the interaction between its ex post and ex ante elements.

To begin with, suppose that all countries do equally well out of trade. Ex ante measures have enabled poor countries to do as well as their wealthier trading partners, but no better. For concreteness, suppose that there are two poor countries $-\mathrm{A}$ and $\mathrm{B}-$ and two rich countries $-\mathrm{C}$ and $\mathrm{D}$. Total gains from trade are 12, and each country receives 3 . Now, according to International Relative Gains, as I have interpreted it, no ex post redistribution is required. Poor countries cannot demand a larger share of the cooperative surplus than they have contributed to creating. This is because no rich country has received more than an equal share, and there are therefore no unjust inequalities to address, no excess gains to be shared. Each co-creating country has received what it is owed.

But this conclusion looks strange. Remember that, had ex ante measures enabled poor countries to secure greater than equal shares for themselves, they would have been entitled to retain those shares. But if pro-poor inequalities secured through ex ante distribution would have been welcomed, why, when such inequalities fail to materialize, can greater gains for poor countries not be provided ex post? (Why should we not advocate for redistribution that would give 4 each to $\mathrm{A}$ and $B$, and 2 each to $C$ and $D$ ?) Why is it that, once a round of trade has been completed, poor countries are entitled to a merely equal share of total gains? James tells us that it is "only fair for developing countries to see greater gains" (James 2012, p. 223). But if this is so, and if we can provide greater gains through ex post redistribution, surely that is what should be done. 
Is there any reason to distinguish between pro-poor inequalities secured through ex ante distribution and pro-poor inequalities secured through ex post redistribution? A believer in free market ideology might maintain that there is. A libertarian might suggest that gains achieved in the market are the fruit of one's own labour, whereas benefits received through ex post redistribution have been stolen from those who produced them. But James would clearly not wish to avail himself of such an argument. The argument simply overlooks the cooperative nature of social production that James is trying to emphasize.

Let us now modify the scenario in order to illustrate a second reservation. This version of the scenario involves three poor countries - A, B, and C - and one rich country - D. Suppose that the three poor countries are comparably situated in terms of development. In a given round of trade, an equal share of the gains "flows" to A (i.e., A gets what it would if the gains were divided equally among all four countries), a less than equal share of the gains flows to $\mathrm{B}$, and a greater than equal share flows to $C$ and D. For concreteness, suppose that total gains from trade are 12 , and that an equal share would therefore mean each country receiving 3 , but that, in fact, A receives 3 , B receives $1, \mathrm{C}$ receives 4 , and D receives 4 . According to International Relative Gains, as I have interpreted it, D's excess gains - the gains it secures over and above what it would get under strict equality - would be redistributed to $B$, which received less than an equal share, whereas C's excess gains would not be touched. The result of this redistribution would be that A receives 3, $\mathrm{B}$ receives 2 , $\mathrm{C}$ receives 4 , and $\mathrm{D}$ receives 3 . This does not look like a satisfactory outcome. Remember that it is "only fair for developing countries to see greater gains.” But B does not see greater gains - it does not even see equal gains - and the proposed ex post redistribution does not change that fact. If fairness demands that developing countries see greater gains, there should be greater redistribution to $\mathrm{B}^{4}$

It does not seem appropriate to "tax" C, a poor country, as this would deprive C of the extra gains to which, ex hypothesi, it is entitled. Rather, the natural way to proceed is to "tax" D more heavily. According to International Relative Gains, as I have interpreted it, it is only the excess gains of rich countries that are to be redistributed. However, in cases like the one I have described, where this kind of limited redistribution would leave some poor countries (in this case, B) with less than an equal share, focusing exclusively on the excess gains of rich countries

4 As an anonymous reviewer noted, there might, in some cases, be conclusive reasons not to allocate greater gains to countries like B. Perhaps some such countries fare so poorly relative to others because they are governed by incompetent rulers whose policies would ensure that any extra gains were squandered. I am assuming that James's claim is that poor countries have a pro tanto entitlement to a greater share. Accordingly, my objection here is that International Relative Gains does not adequately satisfy that pro tanto entitlement. 
seems unduly narrow. We can appeal to the conviction that it is "only fair for developing countries to see greater gains" to make a case for cutting into the equal shares of rich countries.

Notice that, while James occasionally claims that "it is only fair for rich countries to benefit from trade” (e.g., James 2012, p. 223), my proposal need not prevent rich countries from benefitting. Rather, it can merely reduce the size of their benefits in order to increase the benefits received by poor countries. For example, in the case described, we might take an additional 1 from D and redistribute it to B. D would then have 2, and B would have 3, rather than the other way around.

Let us now turn to our third reservation, which concerns the interaction between the ex ante and ex post components of International Relative Gains. The problem I wish to highlight arises as a result of three factors. First, as we noted earlier, and as James acknowledges, (1) the ex ante component of the envisaged scheme - which allows and encourages poor countries to trade to dynamic comparative advantage - may make rich countries worse-off. Rich countries may see their share of total gains shrink. Second, (2) the ex post component of the scheme does not redistribute gains away from countries that are poor. If poor countries can secure a greater than equal share of total gains, they are to be allowed to keep those gains. Third, (3) it is important to note that - even with the ex ante component of the distributive scheme in operation - some poor countries will benefit from trade more than others. In other words, some poor countries will be able to do more with the tools that ex ante redistribution provides. Some poor countries will be able to take great advantage of the freedom to trade to dynamic comparative advantage, while others will not. To capture this point, let us distinguish between poor countries that are successful in trade and poor countries that are unsuccessful in trade.

Now, given the above three points, I submit that unsuccessful poor countries have a reasonable complaint against the proposed distributive scheme. This is because the ex ante component, which, ex hypothesi, does not greatly benefit unsuccessful poor countries in itself, also diminishes what these countries can expect to receive via the ex post component. As per (1) above, the ex ante component redistributes gains from rich countries to successful poor countries. As per (2), this amounts to redistributing gains away from those countries that are required to share their gains (via ex post redistribution) with poor countries (successful and unsuccessful alike), and to countries that are not required to share their gains. ${ }^{5}$ This means that unsuccessful poor countries will receive less through ex post redistribution than they would have done had the ex ante component not 
been in operation. From the perspective of unsuccessful poor countries, it might have been better if their peers had not become successful. ${ }^{6}$

To illustrate, suppose there are two poor countries - A and B - and two rich countries $-C$ and D. Suppose that total gains from trade are 12, and that, if gains were distributed equally, each country would receive 3. Suppose that in the absence of the ex ante component of the distributive scheme, A would receive 1 , B would receive 1 , $\mathrm{C}$ would receive 5 , and $\mathrm{D}$ would receive 5 . Under these circumstances, the ex post component of the scheme would redistribute the excess gains reaped by $\mathrm{C}$ and $\mathrm{D}$ equally among A and B. Each country would then have 3 (see Table 1 below).

Now suppose that, if the ex ante component of the scheme were in operation, $\mathrm{A}$ would initially receive 1 , B would receive 4 , C would receive 4 , and D would receive 3. Under these circumstances, the ex post component would redistribute C's extra 1 to $\mathrm{A}$ but it would not redistribute the extra 1 reaped by $\mathrm{B}$. $\mathrm{D}$ has no excess gains to be redistributed. The result would be that $A$ receives 2 , $B$ receives $4, C$ receives 3 , and $D$ receives 3 . While $B$ (a successful poor country) is better off than it would have been in the absence of the ex ante component, A (an unsuccessful poor country) is worse off (see Table 2 below).

What follows from this? What should be done? One option is to remove the ex ante component of the scheme and rely exclusively on the ex post component. The likely consequence of doing this is that rich countries do better from trade - as poor countries are deprived of opportunities to better themselves - but that these unfavourable market outcomes are corrected by ex post redistribution.

This is not an attractive option. In light of my earlier comments relating to Rawls's advocacy of property-owning democracy, we should acknowledge that there are compelling reasons to provide poor countries with opportunities to help themselves. With good reason, poor countries wish to be agents within the trading

Table 1: Without ex ante component.

\begin{tabular}{llll}
\hline A & B & C & D \\
3 & 3 & 3 & 3 \\
\hline
\end{tabular}

5 I use the phrase "their gains" loosely, as shorthand for "the gains that have accrued to them". I do not mean to suggest that there is necessarily any sense in which the relevant countries can claim ownership of these gains.

6 An anonymous reviewer encouraged me to acknowledge that the achievements of successful poor countries might have beneficial consequences for unsuccessful poor countries. Perhaps, in some cases, the gains that accrue to unsuccessful poor countries as a result of successful poor countries doing well will be greater than the gains that would otherwise have been redistributed to unsuccessful poor countries from rich countries. However, as I will demonstrate in the text, we do not have to choose between these two sources of gain. 
Table 2: With ex ante component.

\begin{tabular}{llll}
\hline A & B & C & D \\
\hline 2 & 4 & 3 & 3 \\
\hline
\end{tabular}

system, not passive recipients of assistance. Removing the ex ante component of the scheme would be contrary to the achievement of this objective.

An alternative option is to change the ex post component of the scheme. This part of the scheme might be changed to permit redistribution away from successful poor countries (as well as from rich countries). If a poor country does well for itself through trade and secures a greater than equal share of total gains, we might allow at least some of these gains to be shared with other poor countries that have done less well. (For example, 0.5 of B's extra 1 might be shared with A.) But this is not an appealing solution either. We do not want to take from those who have little. If taking from those who have little were the only way of assisting those who have even less, then perhaps this would be a tolerable course of action. But this is not the only way of providing assistance. As noted above, an alternative option is to cut into the equal shares of rich countries. This is another scenario where a strong case can be made for doing so. For example, in addition to redistributing C's extra 1 to A, a further 0.5 could be taken from each of $C$ and $D$ and redistributed to $A$. The ex ante component would then still secure additional gains for B (and enhance B's agency), but A would not be worse off than it would have been without the ex ante component (see Table 3 below).

The foregoing discussion has sought to challenge the internal logic of James's position. My claim is that the distributive scheme that I have proposed - which sanctions greater redistribution to the poor - does a better job of satisfying James's own commitments than the scheme he himself envisaged. I have conceded that my interpretation of James's scheme may be mistaken. But regardless of exactly what James had in mind, my hope is that my comments have brought greater clarity to the variety of options that are on the table for those who endorse James's general approach, and also to the relative merits of the reasons that can be adduced in support of those options.

Table 3: With ex ante component; alternative ex post redistribution.

\begin{tabular}{rrrr}
\hline A & B & C & D \\
\hline 3 & 4 & 2.5 & 2.5 \\
\hline
\end{tabular}


So far, I have focused on James's first permissible ground for inequality, which allows poorer countries to see greater gains. I have endeavoured to illuminate what this commitment might (and should) entail. In the next section, I shall continue my internal challenge to James's position by scrutinizing his second proposed ground for permissible inequality.

\section{Against Endowment Sensitivity}

Recall that, according to James, an internationally unequal distribution of the gains from trade is permissible if the inequality tracks differential national endowments. National endowments, remember, are features of countries that are not produced by trade and that affect how much a country can be expected to gain from trade. James tells us that differential national endowments are "a relevant difference among participant countries" (James 2012, p. 221) that can justify departures from equality. Differential endowments are a "ground for inequality" (James 2012, p. 222).

Treating national endowments as a ground for inequality could mean several very different things. For example, it could mean giving a greater than equal share to countries with poor national endowments (such as a weak natural resource base). Alternatively, it could mean allowing countries to retain a greater than equal share if their extra gains are attributable to their national endowments. In other words, recognizing national endowments as a ground for inequality could mean treating certain "losers" more generously when redistributing gains; or it could mean treating certain "winners" more leniently when taxing gains. It soon becomes clear that it is the latter that James has in mind. He is opposed to "redistribution of the benefits that flow from differential endowment” (James 2012, p. 222).

From the standpoint of Rawlsian egalitarianism, this form of "endowment sensitivity" (James 2012, p. 222) is prima facie puzzling. This is because endowment sensitivity, so construed, seems straightforwardly to contradict central Rawlsian tenets about how to distribute the fruits of social cooperation. ${ }^{7}$ Consider what Rawlsians have said about natural talent. At the domestic level, Rawlsian egalitarians do not claim that, because natural talent exists independently of social cooperation, the talented should be permitted to retain a larger than equal share. On the contrary, Rawls famously resisted the claims of the talented to larger shares,

7 In an article on trade justice that predates James's book by over a decade, Frank Garcia appealed to Rawlsian considerations in order to challenge the justice of trade outcomes reflecting inequality in natural endowments. See Garcia (2000, esp. pp. 1016, 1025). 
maintaining that departures from equality should be permitted only if and when they work to the maximal advantage of the worst-off. In this regard, James's theory seems to diverge sharply from Rawls's. This divergence becomes apparent when we observe that some national endowments - such as climate, geography, and natural resources - appear morally analogous to natural talent. They are advantages that are bestowed upon some by mere good fortune. And yet, James's theory permits fortunate nations to retain the larger share of gains that their favourable endowments make possible, and this permission is granted irrespective of whether it can be expected to further the interests of the worst-off.

How, then, is endowment sensitivity to be justified? James offers several arguments in its defence. His first argument appeals to the intuitive judgement that James thinks we are likely to form with regards to one particular national endowment, namely, population size. He writes: "we can see the intuitive idea [behind endowment sensitivity] by comparing a large and small country. It would not seem fair to simply sum up the total gain from trade and divide it equally" (James 2012, p. 222). We can agree with James that a strictly equal distribution of gains between large and small countries might seem unfair. We can also identify plausible reasons to support this intuitive judgement. In large countries, the gains from trade will be spread more thinly. If each country is allocated an equal share of gains, the individual members of high-population countries will receive fewer gains than the individual members of low-population countries.

While these considerations may give us reason to adjust for population size when distributing gains, they do not support adjusting for endowments more generally, as James proposes. From the intuitions that we have about population size, we cannot read off conclusions about how to treat other national endowments. Notice that James's list of endowments is wide-ranging. In addition to population size, it includes things as diverse as "climate, quality of land, geography, level of technological development, productive structures and culture" (James 2012, pp. 180-181). Thus, even if we were to accept as intuitive the call to adjust for population size, it would not follow that we should also adjust for any other items on James's list.

James's second defence of endowment sensitivity directly addresses the apparent inconsistency, flagged above, between his approach and the manner in which Rawlsian egalitarians have treated the individual-level equivalent of national endowments, namely, natural talent. James attempts to address this apparent inconsistency by essentially dismissing the notion of natural talent. He writes: "In domestic society ... beneficial personal endowments are by and large a product of the very system of cooperation whose justification is in question" (James 2012, p. 222). James's claim seems to be that an individual-level analogue to national endowments simply does not exist (or, if it does exist, that its role is too 
trivial to be worth addressing). Thus, James is able to deny that there is any inconsistency between the egalitarianism he recommends internationally and Rawlsian domestic egalitarianism. We are to adjust for national endowments external to international cooperation because such endowments exist; we do not adjust for individual-level endowments external to domestic cooperation because there are no such endowments to adjust for.

Let us assume, for the sake of argument, that James is right, and that talents are "by and large" a product of the social system, not of nature. (I do not think this assumption is correct, but challenging it here would not be the best way of addressing the issue at hand.) If James is right, it follows that the attention paid by Rawls and his followers to natural talent is unwarranted. It is unnecessary to evaluate the normative status of inequality attributable to natural talent if natural talent - and, thus, inequality attributable to natural talent - does not exist. But this fact does not extinguish the underlying Rawlsian concern, which relates to the influence that can be exerted upon distributive shares by endowments bestowed upon some by mere good fortune. James's comments suggest that talents because a product of the social system - are not an example of such endowments, but they do not demonstrate that, where endowments in this general category do exist - as they do in the context of international trade, in the form of national endowments - their influence on distributive shares should be seen as morally unobjectionable. (To be sure, I have not yet fully articulated a reason for thinking that such influence should not be seen as morally unobjectionable. I shall articulate such a reason presently, when considering James's next defence of endowment sensitivity.)

James's third defence appeals to the limited role that he ascribes to the trade regime. James writes: "endowment sensitivity simply reflects the limited aim of trade practice, namely, to improve upon endowments roughly as given ... rather than to redistribute the benefits of those endowments as such" (James 2012, p. 222). This third defence of endowment sensitivity directly invokes James's explicative methodology. Describing that methodology, James writes: "we work out a conception of fairness for, and in part from, the social practice that organizes the global economy as we know it ... We engage in moral reasoning about what fairness substantially requires ... but we do so as framed by our best understanding of the identified practice's distinctive structure and organizing aims" (James 2012, pp. 16-17).

In other words, we cannot expect the trade regime to correct for inequalities traceable to arbitrarily distributed national endowments because that is not what the trade regime is for; its purposes are more limited. According to James, a virtue of his account is that it takes seriously these limitations. By contrast, a more egalitarian approach to trade justice should be dismissed as revisionary, as 
attributing to the trade regime certain purposes for which it was not built (James 2012, pp. 200-201). This prompts two questions. First, does James's own account pass the test that he proposes? Does James's account really take seriously "the limited aim of trade practice" (as he conceives of it)? And second, would a more egalitarian account necessarily fail this test?

In the introductory chapter of his book, James notes the "non-utopian" character of the kinds of normative claims that he seeks to defend. His comments here might be adduced in defence of the claim that his own account would pass his proposed test. He writes: "When people stand up and demand the abolition of impoverishing farm subsidies, or crisis-prone capital markets, or developmentinhibiting WTO rules, as protesters now regularly do, they feel right in doing so in part because they aren't asking for the moon" (James 2012, p. 13).

Now, each of the three demands that James mentions can certainly be reconciled with the limited aim that James attributes to the trade regime. Each demand focuses on features of the global economy that have undermined the ability of certain countries to improve upon their existing endowments. When, for example, rich-world farm subsidies prevent certain impoverished countries from exploiting their comparative advantage in agricultural production, the trade regime is simply not working for the countries in question. It is not delivering on its promise. But notice that, by endorsing the International Relative Gains principle, James goes far beyond the more minimal demands of those who protest against the WTO. As we have seen, International Relative Gains does not merely require that all countries be able to augment their existing endowments; it requires that the gains from trade be distributed in an egalitarian fashion. If principles of trade justice must reflect the aim of trade practice, and if the aim of trade practice is what James says it is, why is International Relative Gains not impugned?

One possible answer to this question is that James's test is less strict than I am imagining. James could argue that the aim of the trade regime must be taken into account when identifying principles of trade justice, but that its aim need not be the decisive consideration. In this spirit, James writes:

While the central, organizing aim of the practice fixes the primary "currency" of distribution [i.e., endowment-adjusted gains], further consequences can be admitted as relevant for argument about what socioeconomic outcomes are fair. Specifically, we may assess any socioeconomic outcomes of a practice in terms of what those affected could reasonably accept or reject. (James 2012, p. 206)

But this prompts a second objection. My first objection was that James's test looks so strict that it will rule out his own favoured principle. Now it looks as though the test is too weak. Why can relatively poorly endowed nations not reasonably reject trade outcomes in which they fare worse than others through no fault of their own? 
In other words, why can they not reject James's proposal in favour of a more egalitarian alternative that seeks to extinguish the influence of morally arbitrary factors? James seems to face a dilemma. If he proposes a version of his test that is strong enough to rule out the more egalitarian principles that he wishes to reject, he risks also ruling out the principle he favours. Alternatively, if James weakens his test to ensure that his own principle is accepted, he then seems to open the door to a more egalitarian rival.

The egalitarian rival that I am envisaging appeals to concerns about moral arbitrariness. As we have seen, James has methodological misgivings about such appeals. As noted above, James thinks that our arguments should be "framed by our best understanding" of the trade regime as it currently exists. James suggests that concerns about moral arbitrariness cannot be framed in this way. Such concerns are likely to reflect "external" principles that might be applied to the trade regime from outside - in the manner proposed by applicative theories of trade justice - but which cannot be grounded in the trade regime's distinctive features, and are therefore contrary to James's explicative approach (James 2012, p. 241).

However, the concerns I am pressing need be no more "external" than the considerations that motivate International Relative Gains. We can accept that the trade regime is a cooperative endeavour yielding a joint product co-created by all participating nations, and we can then ask why participating nations cannot reasonably reject outcomes that fail to track any morally relevant factors. Moreover, our account of "moral relevance" can be informed by our conception of the trade regime. For example, "level of cooperation" or "degree of integration" might be morally relevant. If, say, country A fares better than country B because B maintains higher tariffs, perhaps A's extra gains need not be regarded as morally arbitrary. By contrast, the mere good fortune of entering the practice with superior endowments bestowed by Mother Nature can be regarded as morally arbitrary. Good fortune does not give any participant a legitimate claim to a greater share of the socially created product.

Before I conclude, one further point should be made. When James considers the case for principles more egalitarian than his own, he often assumes that such principles will be individualistic in character. That is, he assumes that such principles will identify individuals rather than nations as the appropriate beneficiaries of distribution (James 2012, pp. 11-14). He offers several reasons for rejecting such individualism. But notice that these considerations are irrelevant to the present discussion. I have not sought to discredit James's account of the correct beneficiaries of distributive principles. Rather, my target has been the content of those principles. I have assumed, for the sake of argument, that James is right to identify nations as the correct beneficiaries, and then questioned why the nations 
in question - as cooperating participants in the trade practice - should be treated in the particular way that James recommends.

\section{Conclusion}

I have suggested that the arguments provided by Aaron James - the best-known defender of the explicative approach to egalitarian trade justice - fail to rule out and, in some cases, positively support - egalitarian conclusions stronger than those that James in fact endorses. If my arguments are successful, they show that James's trade egalitarianism is unduly minimalistic. However, I have not claimed that the explicative approach can endorse egalitarian conclusions that are as strong as those suggested by the applicative alternative described in the introduction. I have already noted one aspect of the explicative approach that serves as an obstacle to such endorsement. I mentioned that while advocates of this approach can support redistributive efforts to eliminate inequalities of gain attributable to morally arbitrary factors, their conception of moral arbitrariness must be constrained by their conception of trade practice, and is therefore likely to be narrower than that adopted by advocates of the applicative approach. I will finish by noting a further aspect of James's account that limits the degree of egalitarianism that he can embrace.

In the introduction, I noted that there are reasons to favour a distribution of the gains from trade that is not equal but equalizing. There are large economic inequalities between the countries that participate in the trade regime, and these inequalities can be reduced by distributing a larger share of gains to those that are worse-off. An equalizing distribution seems obviously appropriate from the perspective of the applicative approach. This is because that approach begins from a commitment to equality as an important goal that we should strive to achieve. But we saw that James's explicative approach also recommends measures that have an equalizing effect. James believes that inequality of gain is to be welcomed when a larger share is received by countries that are poor. He suggests that it is "only fair for developing countries to see greater gains." Nevertheless, while James's preferred distributive scheme has an equalizing effect - it reduces inequality between rich and poor countries - it lacks an equalizing rationale. James argues that poor countries should be permitted to retain a larger share of gains because, in virtue of their citizens' more urgent needs, their interest in greater gains is more significant than that of richer countries (James 2012, pp. 222223). From James's perspective, greater gains to poor countries are to be welcomed 
because "the benefits of trade matter more ... the worse off the beneficiaries are in absolute terms", not because it is important to close the gap that exists between poor countries and their better-off counterparts (James 2012, p. 223). Consequently, even granting the arguments that I made in Section 2, James's account is likely to justify a smaller amount of equalizing than the applicative alternative.

This does not rule out the possibility of an alternative explicative account that could be more strongly egalitarian than James's. As I noted in the introduction, while advocates of the explicative approach do not begin from a general commitment to international equality, they can have reasons to be concerned about inequalities between countries qua participants in the trade practice. Like economic inequalities that exist in other settings, economic inequalities between trading countries can translate into inequalities of power. Richer trading countries are better placed to push for trade agreements favourable to their own interests, and to maintain features of the trade regime that further entrench their advantages. Since this is likely to undermine things that advocates of the explicative approach can have reasons to care about - such as the capacity of poor countries to be selfdirecting agents within the trade system - some might support equalizing measures as a means of combatting asymmetric power relations. Indeed, some may be willing to support equalizing measures more ambitious than those endorsed by James - and perhaps more ambitious than those that I have urged James to embrace.

These concluding remarks are merely suggestive. As I have stressed, my aim in this paper is not to argue that the explicative approach can endorse the egalitarian maximalism associated with the applicative alternative. Rather, my aim has been to show that the best-known defence of the explicative approach can support egalitarian proposals stronger than those that its author has in fact accepted. The explicative approach can thus yield a form of trade egalitarianism that is closer in strength to the trade egalitarianism associated with the applicative approach. Whether the gap between the egalitarian proposals of each approach can be reduced even further is a question for another occasion.

Acknowledgements: An earlier draft of this paper was presented at a conference hosted by the University of Oslo. I am grateful to participants for their valuable feedback, and especially to Erik O. Eriksen, who acted as my discussant. For helpful discussion, I am grateful to Simon Caney, Tom Parr, and Hallvard Sandven. I also owe a debt of gratitude to three anonymous reviewers for this journal, each of whom provided useful comments. 


\section{References}

Armstrong, C. 2013. "Natural Resources: The Demands of Equality." Journal of Social Philosophy 44 (4): 331-47.

Beitz, C. 2001. “Does Global Inequality Matter?” Metaphilosophy 32 (1/2): 95-112.

Brandi, C. 2014. "On the Fairness of the Multilateral Trading System." Moral Philosophy and Politics 1 (2): 227-47.

Christensen, J. 2017. Trade Justice. Oxford: Oxford University Press.

Garcia, F. J. 2000. "Trade and Inequality: Economic Justice and the Developing World." Michigan Journal of International Law 21 (4): 975-1049.

Garcia, F. J. 2003. Trade, Inequality, and Justice: Towards a Liberal Theory of Just Trade. Leiden: Brill.

Gerhart, P. M. 2002. "Slow Transformations: The WTO as a Distributive Organization." American University International Law Review 17 (5): 1045-96.

James, A. 2012. Fairness in Trade: A Social Contract for a Global Economy. New York: Oxford University Press.

James, A. 2017. “Fortune and Fairness in Global Economic Life.” Journal of Moral Philosophy14 (3): 270-90.

Moellendorf, D. 2005. “The World Trade Organization and Egalitarian Justice.” Metaphilosophy 36 (1): 145-62.

Rawls, J. 1999. A Theory of Justice, Revised ed. Cambridge: Harvard University Press.

Rawls, J. 2001. Justice as Fairness: A Restatement. Cambridge: Harvard University Press.

Ronzoni, M. 2009. "The Global Order: A Case of Background Injustice? A Practice-Dependent Account.” Philosophy \& Public Affairs 37 (3): 229-56.

Suttle, 0. 2017. Distributive Justice and World Trade Law: A Political Theory of International Trade Regulation. Cambridge: Cambridge University Press. 